\title{
A démarche estratégica: a metodologia de gestão do Centro Hospitalar Regional Universitário de Lille, França
}

\author{
The strategic management: the methodology \\ applied by the "Centre Hospitalier Regional \\ Universitaire" (CHRU) at Lille, France
}

Francisco Javier Uribe Rivera 1

1 Escola Nacional de Saúde Pública,

Fundação Oswaldo Cruz. Rua Leopoldo Bulhões 1480, 7 o andar, Rio de Janeiro, RJ 21040-210, Brasil.
A bstract This work is a general presentation of the "Démarche Stratégique", a strategi c process applied by the "Centre Hospitalier Régi onal Universi taire" (CHRU) at Lille, France. The hospital management methodology relies on the strategic analysi s of the best alternatives for rationalizing the hospital mission. It takes into account a competitive environment, in which it is necessary to structure heal th care networks based on the negotiation of inpatient care goals. Theauthor presents the phases and main methodological tools of the approach, as well as a preliminary evaluation of its potentials.

Key words Strategic Planning; Hospital Management; Heal th Care Profile; Public Health

Resumo Este trabalho é uma apresentação geral do enfoque da "démarche" estratégica (o processo estratégi co), aplicado pel o Centro Hospitalar Regional Universitário (CHRU) de Lille, França. Este é um método de gestão hospitalar, baseado na análise estratégi ca das mel hores alternativas de racionalização da mi ssão hospital ar. Consi dera um ambiente de competi ção, onde é necessári o estruturar redes de cuidados com base na negociação dos projetos de estabel ecimento. $\mathrm{O}$ autor apresenta as fases e os princi pais instrumentos metodológicos do enfoque e faz uma avaliação preliminar de possibilidades.

Palavras-chave Planejamento Estratégi co; Gestão Hospitalar; Perfil Assistencial; Saúde Pública 


\section{Introdução}

O objetivo deste trabalho é apresentar, em grandes linhas, a proposta metodológica da Démarche Stratégique - o termo démarchesignifica processo, trâmite, gestão: a gestão estratégica? -, enfoque de elaboração do projeto de estabelecimento (ou projeto médico)do Centro Hospitalar Regional Universitário (CHRU) de Lille, Norte da França. A realização de uma visita a essa estrutura hospitalar nos possibilitou conhecer este importante instrumento de gerenciamento que ora divulgamos.

Baseado na obra "Le Management Stratégique Hospitalier" de M. Cremadez (1992), este enfoque se propõe a definir racionalmente a missão de um hospital, situando-o na perspectiva ideal de uma rede coordenada de cuidados de saúde, o qual equivale ao entendimento da organização hospitalar enquanto uma organização proativa, centrada sobre o exterior, que assume o ambiente como recurso (e não como restrição). Isto significa que a definição da missão terá que ser negociada com o ambiente externo institucional (incluindo os outros hospitais da área). Desta maneira, o proativo se refere à capacidade de atuar dinamicamente sobre o ambiente.

As características das organizações sanitárias tendem naturalmente para um padrão que se distancia do ideal. O processo de autonomia dos centros operacionais, decorrente de uma sorte de ruptura entre a direção estratégica e estes últimos, a extrema diferenciação ou atomização de suas estruturas internas em função da especialização do trabal ho e uma desconsideração relativa da ambiência externa em razão de uma sobrevalorização corporativa do interno são traços que conspiram contra a possibilidade de um projeto gerencial que enfatize a integração intra-institucional, a racionalidade econômica da missão específica e a negociação de uma rede de cuidados com os outros estabelecimentos da ambiência imediata. A perspectiva da démarche é a de promover um tipo de movimento cultural que contrabalance essas tendências, abrindo caminho para o desenvolvimento de uma forma de organização que se aproxime daquelas premissas ideais.

Mais especificamente, os objetivos da dé marcheseriam:

- promover um elo de ligação entre a gerência estratégica e os centros assistenciais, através da comunicação;

- definir a missão do hospital de acordo com o critério de oportunidade, o qual equivale a determinar exclusivamente um padrão de atividades que Ihe permita vantagens comparativas;
- ensejar um lugar de comunicação, onde os atores-serviços possam chegar a definir um projeto coletivo;

- favorecer a integração do hospital em uma rede de oferta de cuidados estruturada com a preocupação da eficácia e da eficiência;

- promover um processo de transformação cultural progressiva, não necessariamente preso à busca de objetivos instrumentais, imediatos.

A démarcheéum método que supõe a adaptação de um enfoque empresarial ao setor público de serviços de saúde. É um enfoque de planejamento ou de gestão estratégicos de natureza microeconômica, baseado em autores como o próprio Cremadez (1992), Michel Crozier \& Erhard Friedberg (1977), M. E. Porter (I982), M. Thevènet (1993), entre outros.

\section{Método}

As fases do método (e seu conteúdo geral) são as seguintes:

- A análise do existente: corresponde ao diagnóstico do método.

- A segmentação: esta etapa corresponde à definição dos principais agrupamentos homogêneos de atividades, considerados aqueles que apresentam uma mesma problemática estratégica.

- A análise do valor e da posição estratégica (competitiva) de cada um dos segmentos: o valor equivale à capacidade de atração do segmento, ao interesse que o mesmo teria para o estabelecimento em função de uma política geral; a posição competitiva é avaliada considerando-se o grau de controle sobre os chamados fatores-chave de sucesso, que corresponderiam a vantagens ou situações positivas que é necessário possuir para ter êxi to em uma atividade.

- A construção do porta-fólio de atividades, visando à definição da estratégia geral de atuação ou dos objetivos: o porta-fólio é um gráfico cuja abscissa está representada pela posição competitiva do estabelecimento e cuja ordenada representa-se pela capacidade de atração (valor), em que são posicionados os segmentos. - O plano de ações, visando a atingir os objetivos, definidos em termos de três possibilidades- priorizar o desenvolvimento de um segmento; estabilizá-lo; reduzir o recrutamento de clientela para um segmento de atividades.

- A montagem dos indicadores de monitoramento do plano.

Vejamos o conteúdo mais específico de cada fase. 


\section{A análise do existente}

O diagnóstico é administrativo e médico.

O diagnóstico administrativo é do tipo tradicional, com informação como: tempo médio de permanência, número de ingressos, pessoal médico e paramédico etc.

O diagnóstico médico compreende:

- relação de patologias atendidas por disciplina médica;

- relação de tecnologias utilizadas por disciplina;

- cruzamento entre patologias e tecnologias (grade específica);

- relação das modalidades de atenção, considerando quatro critérios:

1) se as atividades visando às patologias são programáveis (planejadas com uma semana de antecedência) e/ ou não programáveis;

2) se a intervenção sobre as patologias demanda consulta e/ ou hospitalização;

3) o tipo de hospitalização requerida: menos de 24 h; de $24 \mathrm{~h}$ a cinco dias; de cinco a 12 dias; mais de 12 dias;

4) se as patologias concernidas demandam um tipo particular de capacidade diagnóstica ou de exploração funcional (plateau tecnique) existente no serviço ou fora dele.

Esta fase diagnóstica inclui ainda a relação dos concorrentes e dos parceiros, bem como o desenho da rede ou fileira de cuidados (filière desoins).

A rede de cuidados (Tabela 1) é um quadro que pretende levantar as atividades por segmento, divididas em atividades de diagnóstico, tratamento e acompanhamento, realizadas no serviço, em outros serviços do mesmo hospital e na rede (interfaces externas).

A filière de soins é um instrumento que possibilita identificar superposições e complementaridades eventuais entre os três níveis de serviços referidos, possibilidades de concorrência e também carências de atividades.

O objetivo maior desta fase diagnóstica é proporcionar elementos para a fase seguinte, que consiste em segmentar os serviços segundo uma lógica que veremos a seguir.

\section{A segmentação estratégica}

Como antecipamos, a segmentação implica definir coletivamente, no nível de cada serviço, agrupamentos homogêneos de atividades, definidos como aqueles pólos de atividades onde predomina a identidade de elementos do ponto de vista de sua problemática estratégica. Neste processo, devem-se reduzir ao mínimo possível os fatores de discrepância, de modo
Tabela 1

\begin{tabular}{|c|c|c|c|}
\hline \multirow[t]{2}{*}{ Segmento } & \multicolumn{3}{|c|}{ Rede de Cuidados (Filière de Soins) } \\
\hline & Diagnóstico & Tratamento & Acompanhamento \\
\hline \multicolumn{4}{|l|}{ Serviço } \\
\hline \multicolumn{4}{|c|}{ CHRU (outros serviços) } \\
\hline $\begin{array}{l}\text { Rede } \\
\text { (interfaces externas) }\end{array}$ & & & \\
\hline
\end{tabular}

Fonte: UAS-CHRU, 1995a

que a presença de diferenças notórias deve ser considerada causa de uma eventual resegmentação ou divisão de categorias.

O objetivo central do estabelecimento de segmentos homogêneos é criar categorias que permitam uma análise estratégi ca representativa, tendo em vista que o hospital é uma firma multiproduto, onde nem sempre todos os grupos de atividades apresentam o mesmo desenvolvimento ou o mesmo valor estratégico. Neste sentido, considera-se que cada segmento reconhece um ambiente concorrencial específico.

A fase da segmentação é uma análise multicritérios, em que as diferentes atividades são submetidas ao crivo de quatro critérios:

- patologia;

- tecnologia;

- modos de atenção;

- população.

Esta análise é progressiva, começando pelos critérios médicos: patologia e tecnologia. Esgotadas as possibilidades de segmentação em função de um critério, passa-se sucessivamente à anál ise em função dos outros. Considera-se que o critério modos de atenção reflete questões gerenciais e que o critério população permite introduzir uma racionalidade social na escolha.

Busca-se, então, criar agrupamentos homogêneos do ponto de vista dos quatro critérios, e não de um em particular. A definição, porém, é situacional, tendo em vista que os envolvidos podem privilegiar um determinado critério ou dois. Fatores de natureza subjetiva fazem parte, inevitavelmente, desta escolha, que não é universal e permanente. O processo é iterativo, progressivo e exploratório.

A título de ilustração, eis aqui um exemplo de segmentação em uma disciplina médica (fonte: UAS-CHRU, 1995b):

Hematologia

- Leucemias agudas.

- Linfomas não hodgkinianos de grau severo.

- Linfomas não hodgkinianos de grau fraco e doença de Hodgkin. 
- Doenças não submetidas à quimioterapia, mas que colocam problemas agudos que demandam uma hospitalização (como he mofilias e PTAI).

- Consultas.

- Enxertos ou transplantes.

- Pesquisa.

Comentário do consultor envolvido nesta experiência: esta segmentação está baseada nos critérios patologia e modos de atenção, com uma individualização, ainda, da atividade de pesquisa.

Segundo opinião de técnicos do CHRU, predominam, na prática, os critérios médicos, não devendo ser necessariamente assim. Em geral, o que se observa é um agrupamento que implica a combinação de vários critérios, com a predominância de alguns.

A nálise do valor de cada segmento e de sua posição estratégica

A determinação do valor implica analisar cada segmento segundo vários critérios genéricos (com subcritérios). Os principais são:

- estado atual e perspectivas do mercado;

- as barreiras à entrada;

- as sinergias;

- o grau de motivação interna;

- as oportunidades do ambiente;

- as potencialidades do segmento.

Cada critério genérico teria um peso determinado (em termos percentuais) na fixação do valor do segmento (assim como os subcritérios específicos). Este peso é variável, situacional. Através de um sistema de notação, atribui-se um valor por critério ao segmento em foco (de 0 a 20). O valor global do segmento será função das notas por critério e de seu peso específico.

Para ilustrar, daremos alguns exemplos de subcritérios.

Em relação ao mercado, consideram-se as perspectivas de desenvolvimento, o risco de flutuação e a intensidade da concorrência.

Em relação às barreiras de entrada, considera-se fundamentalmente o montante do investimento envolvido no desenvolvimento dos segmentos e as possibilidades de rentabilização.

A atribuição de uma nota ao segmento por (sub)critério está baseada na formulação de perguntas-chave. Por exemplo, a avaliação das perspectivas de desenvolvimento supõe a pergunta:

A atividade em questão irá progredir nos próximos anos...

- em função dos fatores de risco (idade, por exemplo) ou
- em função da evolução tecnológica ou do savoir-faire (novas terapêuticas)?

Uma nota forte corresponderia à previsão de um forte crescimento e uma nota fraca à estimativa de uma diminuição importante.

A matriz básica, adaptada, da determinação do valor é apresentada na tabela 2 .

O objetivo central da análise do valor é hierarquizar os segmentos por meio de uma ponderação de critérios e de uma notação relativa.

O resultado desta fase é uma descrição precisa da problemática específica do segmento. Este método, apesar de não partir da categoria problema, permite, nesta fase, ir ao encontro dos problemas específicos. Por exemplo:

- muitos concorrentes, determinando uma nota fraca no tocante à intensidade da concorrência, o que contribui para um valor de mercado relativamente menor;

- expectativa de poucos aportes externos, comprometendo o item oportunidades do ambiente;

- fraco desenvolvimento da pesquisa, comprometendo as potencialidades de desenvolvimento geral.

A análise da posição competitiva ou estratégica do hospital corresponde à análise dos fatores-chave de sucesso, à análise do grau de controle relativo dos mesmos.

O objetivo central desta definição é hierarquizar as ações-chave (os segmentos) em função de sua posição concorrencial.

O método de análise consiste dos seguintes passos:

- identificação dos fatores-chave de sucesso;

- levantamento dos concorrentes;

- ponderação dos fatores-chave de sucesso (definição do seu impacto ou de seu peso sobre a posição concorrencial);

- notação.

A identificação dos fatores-chave de sucesso é equivalente à definição situacional de elementos de capacidade discriminante, ou seja, de capacidades específicas de ordem relacional, tecnológica, financeira ou de competências, cuja posse garante posições de vanguarda.

A matriz de análise do controle dos fatoreschave de sucesso (com exemplos) é a tabela 3.

\section{A construção do porta-fólio de atividades:}

Definidos o valor e o grau de controle dos fatores-chave de sucesso, estas duas variáveis são cruzadas sob a forma de um gráfico onde os segmentos são colocados, de modo a permitir uma visualização da posi ção estratégica de cada um deles (Figura 1). 
É importante assinalar que o tamanho da superfície dos segmentos corresponde à expressão deles em termos de volume de produção ou de atendimento. No porta-fólio acima teríamos dois segmentos hipotéticos no quadrante de baixo valor e baixo controle de fatores e dois no quadrante de alto valor ou alta capacidade de atração e alta posição competitiva.

Em geral, deveriam ser estimulados os segmentos de alto valor. Por outro lado, quando os segmentos apresentam uma baixa capacidade competitiva, significa que é necessário realizar muitos progressos. O ideal é encontrar os segmentos à direita do porta-fólio. Porém, como nos foi informado na Unidade de Análise Estratégica, o porta-fólio não deve ser encarado como um documento mecânico: ele é um documento para pensar.

O porta-fólio serve para determinar prioridades, para fixar a estratégia do hospital em termos de três possibilidades de objetivos:

- Desenvolver um segmento.

- Manter ou estabilizar um segmento.

- Reduzir o recrutamento de um segmento.

\section{Elaboração dos planos de ação}

Os planos de atividades visam a concretizar os objetivos definidos a partir do porta-fólio de atividades.

Grosso modo, estes planos incluem os esforços a realizar para agir sobre a rede de médicos de consultório, para implementar associações, para formar médicos e pessoal paramédico, para comunicar o savoir-fai recontrolado, para adquirir novas tecnologias, para implementar novos modos de atenção etc.

Neste momento, retorna-se à análise do vaIor e da posição competitiva dos segmentos para se definirem ações visando a aumentar o valor de algum segmento através da incidência sobre al guns dos critérios contemplados para avaliar a atração, em torno dos quais foram constatados problemas, e melhorar a posição competitiva, mediante a busca do aumento do controle sobre os fatores de sucesso.

Finalmente, a démarche se "encerra" com a definição dos indicadores de acompanhamento das atividades definidas.

\section{Avaliação das dificuldades encontradas}

Os dados desta avaliação foram colhidos na Unidade de Análise Estratégica do hospital, nos encontros mantidos durante nossa visita, e por meio dos documentos citados que fazem parte do material instrutivo do enfoque.
Tabela 2

\begin{tabular}{|c|c|c|c|}
\hline \multicolumn{4}{|c|}{$\begin{array}{l}\text { Atividade ou Disciplina: } \\
\text { Segmento: } \\
\text { Avaliação do Valor do Segmento: }\end{array}$} \\
\hline Critérios de avaliação & $\begin{array}{l}\text { Peso } \\
\%\end{array}$ & $\begin{array}{c}\text { Nota } \\
(\text { de } 0 \text { a } 20)\end{array}$ & $\begin{array}{c}\text { Score } \\
(=p \times n)\end{array}$ \\
\hline \multicolumn{4}{|l|}{ Mercado } \\
\hline \multicolumn{4}{|l|}{ Crescimento } \\
\hline \multicolumn{4}{|l|}{ Risco de flutuação } \\
\hline \multicolumn{4}{|l|}{$\begin{array}{l}\text { Intensidade } \\
\text { concorrencial }\end{array}$} \\
\hline \multicolumn{4}{|l|}{$\begin{array}{l}\text { Valor ponderando } \\
\text { mercado }\end{array}$} \\
\hline \multicolumn{4}{|l|}{ Barreiras de entrada } \\
\hline \multicolumn{4}{|l|}{ Sinergias } \\
\hline \multicolumn{4}{|l|}{$\begin{array}{l}\text { Grau de motivação } \\
\text { interna }\end{array}$} \\
\hline \multicolumn{4}{|l|}{$\begin{array}{l}\text { Oportunidades } \\
\text { do ambiente }\end{array}$} \\
\hline \multicolumn{4}{|l|}{$\begin{array}{l}\text { Potencialidades } \\
\text { do segmento }\end{array}$} \\
\hline Valor do segmento & 100 & & \\
\hline
\end{tabular}

Adaptado a partir de Cremadez, M. \& Grateau, F. (1992)

\begin{tabular}{l} 
Tabela 3 \\
\hline Segmento \\
\begin{tabular}{|l|c|c|c|c|c|c|c|}
\hline Fatores-chave de sucesso & Peso & Nota & A & B & C & D & E \\
\hline $\begin{array}{l}\text { Recursos tecnológicos } \\
\text { Recursos humanos } \\
\text { Relação equipe/paciente } \\
\text { Atividades científicas } \\
\text { Insumos }\end{array}$ & & & & & & & \\
\hline Score segmento & 0 & 0,00 & 0,00 & 0,00 & 0,00 & 0,00 & 0,00 \\
\hline Posição relativa & & & & & & & \\
\hline
\end{tabular}
\end{tabular}

O bs: Estes fatores-chave foram definidos durante a aplicação de Démarche no Hospital da Posse (Nova Iguaçú), na Pediatria (1996).

Entre as dificuldades gerais, destacam-se: o esceticismo, as barreiras de linguagem, a desconfiança, a indiferença e a recusa a comprometer-se.

Em relação ao diagnóstico, as maiores dificuldades residem na ausência de sistemas de informação ao início da démarche, na opacida- 
Figura 1

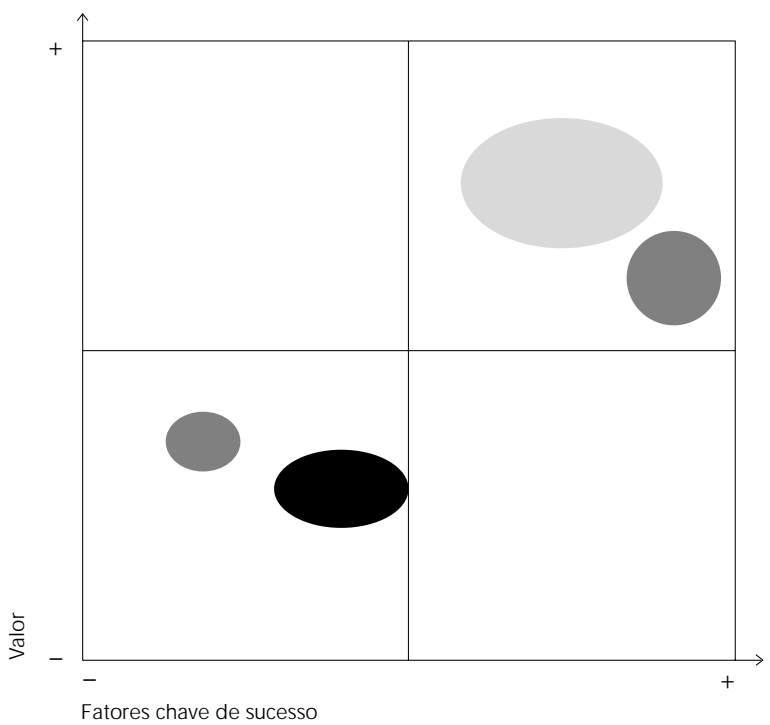

Adaptado a partir de Cremadez, M. \& Grateau, F. (1992)

de da atividade da concorrência, na seletividade da informação qualitativa, na debilidade da base documental e na pobreza dos dados epidemiológicos.

Na fase da segmentação, alguns problemas se tornam evidentes:

- a segmentação é um conceito difícil de apreender: o grupo médico tende a confundir segmento e grupo homogêneo de doença, em circunstâncias que a segmentação das práticas de trabalho pode obedecer a outros critérios (como o tecnológico, o gerencial e o populacional), para além do critério entidade epidemiológica. Isto gera algumas reticências da parte daquele grupo profissional.

- a linguagem utilizada se afasta do vocabulário médico;

- há uma tendência para definir uma segmentação "territorial", reflexo de uma luta pelo poder ou reveladora de problemas latentes.

Sobre a fase da análise estratégica, outros problemas foram detectados:

- a lógica das grades não é facilmente percebida, há uma interrogação múltipla sobre a utilidade da ponderação e da notação;

- a notação é considerada definitiva quando todos os segmentos são examinados;

- os comentários devem ser objeto de um consenso absoluto, o que torna a formalização pesada;

- os serviços em posição de monopólio se prestam menos a este tipo de análise;
- surge a necessidade da busca de informações adicionais.

O processo de elaboração dos planos, finalmente, enfrenta algumas dificuldades:

- os objetivos são às vezes fluidos por falta de comprometimento:

- ausência de participação de outros ofícios do hospital;

- planos de ação de natureza essencialmente médica, sem ligação com um projeto social;

- indicadores às vezes difíceis de pôr em prática.

\section{A nálise crítica geral}

Em primeiro lugar, é importante colocar que um dos maiores méritos da démarche tem sido o de ensejar a definição de objetivos médicos e desenvolver a avaliação. O grande objetivo da busca de uma articulação gerencial de um projeto médico é, em grande medida, cumprido. Durante a nossa visita à Unidade de Análise Estratégica do $\mathrm{CHRU}$, pudemos levantar e revisar os Projetos de Estabelecimento concluídos ao longo de quatro anos de aplicação exaustiva da démarche. Praticamente todos os serviços dos vários hospitais desta verdadeira holding hospitalar foram envolvidos nesta lógica gerencial. Os estágios de desenvolvimento do projeto da démarche variam de serviço a serviço. Porém, esta nova racionalidade gerencial já é uma uma nova realidade, reconhecida na França como um modelo de gestão.

A aplicação da démarche não é um processo apenas formal, que se resuma à documentação pertinente aos projetos de estabel ecimento centralizados na Unidade de Análise Estratégica. Sua lógica de implementação, baseada em reuniões colegiadas, insere-se no objetivo de ensejar uma comunicação ampla a serviço de uma mudança cultural. O desafio implícito é articular um coletivo em torno de um projeto único, que considere a rede. Os resultados da démarche medem-se ao longo do tempo, em um processo progressivo, interativo, sempre exploratório, capaz de impactos culturais decisivos. Isto não é uma tarefa fácil, assimilável à condição de uma gestão racionalizadora ou estabilizadora, de efeitos imediatos. Trata-se da construção da colaboração.

A coordenação da Unidade de Análise Estratégica garante, no entanto, a existência de resultados palpáveis, a serem divulgados em trabalhos em vias de publicação, que nos foram mostrados e que rastrearemos futuramente. A produção de resultados instrumentais, situados na lógica da otimização da alocação de 
recursos e da colaboração com a rede, é, sem dúvida, uma necessidade prática, premente, de caráter legitimador.

Problematizemos um pouco mais o enfoque.

Uma das principais restrições à démarche, surgida nas nossas discussões, refere-se ao fato eventual de que a segmentação estratégica da démarche reforça a atomização, ao invés de ajudar a integração. Esta crítica é bastante séria e merece uma discussão. Há uma tendência no sentido de que a segmentação se paute pela especialização do conhecimento médico e pela disputa de territórios. A aplicação geral do enfoque é feita serviço por serviço, disciplina por disciplina. A análise estratégica dos segmentos é um trabalho feito no nível de pequenos grupos. Surge a pergunta: quem faz a agregação, a coordenação horizontal, a fim de garantir um projeto integrado, prioridades únicas por estabelecimento? Com base nas conversações que mantivemos na UAS, podemos assinal ar que a necessidade da integração depende de uma dinâmica que obriga a agregar e desagregar iterativamente os grupos de trabal ho e a procurar instâncias de discussão mais abrangentes, que superem o microcosmo do segmento, da disciplina e até do hospital. Um dos grandes desafios do método tem a ver com a existência de fóruns ampliados de agregação de interesses, onde se processe o grande acordo ou a grande negociação do projeto médico, imanente à lógica da démarche.

Se, de um lado, a segmentação pode ser considerada um fator de diferenciação, não é menos verdadeiro, por outro lado, que éa partir da categoria celular de segmento que a démarche procura costurar a idéia de uma rede integrada de oferta de cuidados. Este paradoxo real ou aparente alude a um dos objetivos nucleares do enfoque, qual seja transformar o hospital em uma organização aberta. Desta maneira, procuramos sustentar o argumento de que a segmentação estratégica é a base de um processo contraditório, no qual a busca da integração é um dos requisitos essenciais, a ser garantido pelo tipo de metodologia política especificamente implementada na busca da cooperação.

Uma das dificuldades que nos parece mais destacada diz respeito à difícil aplicação da démarche em situações de monopólio. Parecenos que a démarche francesa supõe um contexto de abundância de recursos e de competição, situação que nem sempre se dá nos países em vias de desenvolvimento. Pode-se argumentar que em alguns espaços desses países vigoram essas condições de contexto, mas não em todos. Esta situação não invalida o enfoque, apenas o restringe em sua aplicação.
De qualquer maneira, a perspectiva de aplicação da démarche dependeria de simplificações e adaptações ao nosso contexto. Vamos referir-nos, em geral, às principais reformulações que seriam necessárias, de acordo com as discussões preliminares desenvolvidas no nosso âmbito.

Tudo indica que uma simplificação e uma adaptação dos critérios envolvidos na determinação da capacidade de atração se tornam necessárias. Na realidade, a relação de critérios e o seu peso específico são variáveis ajustáveis no método, em função das características do mercado de serviços de saúde em pauta, em cada momento. Nesta medida, a idéia de se trabalhar com um elenco menor de variáveis representativas, cuidadosamente escolhidas, é algo absolutamente normal, tendo em vista o contexto local e as possibilidades de manuseio da metodologia.

Outro aspecto que pode ser objeto de adaptações tem a ver com a definição de objetivos. O método original não prevê, pelo menos explicitamente, a criação de (absolutamente) novos segmentos como objetivo. Dada a necessidade eventual de se abrirem novos serviços, em função de carências sanitárias, situação que é comum em países com poucos recursos, a estratégia deveria acrescentar às três dimensões de objetivo do enfoque (desenvolver, estabilizar, reduzir) a meta da criação de novas atividades.

Nesta linha de raciocínio, consideramos necessário reforçar os critérios populacionais e epidemiológicos, para contrabalançar as características da démarche que têm a ver com um modelo típico de planejamento baseado na oferta. Esses critérios ligados à detecção de necessidades de saúde deveriam ser levados em conta de maneira mais explícita na análise da possibilidade de abertura de novos grupos de atividades e na análise do valor dos grupos de atividades (re)organizados valendo-se da estrutura da oferta preexistente.

Com estas considerações gerais, concluímos aqui nossa apresentação panorâmica da démarche, não sem antes afirmar que vemos este enfoque como um modelo de gestão estratégica e comunicativa da realidade hospitalar com enormes possibilidades práticas, como nos dispomos a demonstrar na continuidade de nossa pesquisa. 


\section{Referências}

CREMADEZ, M. \& GRATEAU, F., 1992. Le Management Stratégique Hospitalier. Paris: Inter Éditions.

CROZIER, M. \& FRIEDBERG, E., 1977. L'Acteur et le Système. Paris: Éditions du Seuil.

PORTER, M. E., 1982. Choix Stratégi ques et Concurrence. Paris: Ed. Economica.

THÉVENET, M., 1986. Audit dela Culture d'Entreprise. Paris: Éditions d'Organisation.

UAS-CHRU (Unité d'Analyse Stratégique - Centre Hospitalaire Régional Universitaire), 1995a. La Démarche Stratégique. Guide Méthodologique. Material Instrucional. Lille: UAS-CHRU. (Mimeo.) UAS-CHRU (Unité d'Analyse Stratégique - Centre Hospitalaire Régional Universitaire), 1995b. La Démarche Stratégi que. Sommaire. Material Instrucional. Lille: UAS-CHRU. (Mimeo.) 